Ilana Heineberg*

Université Bordeaux Montaignes

\title{
Apesar do silêncio: heranças da experiência da Shoá de Chaim Pomerancblum
}

Resumo:

Este ensaio pessoal tem um duplo objetivo de relatar a transmissão transgeracional da história de vida do sobrevivente da Shoá, Chaim Pomerancblum, e, ao mesmo tempo, de refletir sobre essa prática não canônica no mundo acadêmico e sobre o uso da primeira pessoa. Num primeiro momento, discutirei e explicarei esta abordagem autoreflexiva que se inspira em obras literárias e teóricas pós-memoriais. A seguir, narrarei de maneira fragmentária e metatextual a história de vida de Chaim, meu avô materno.

Palavras-chave:

Shoá, pós-memória, narrativização, testemunho

\section{Abstract:}

This personal essay has a dual purpose of relating the transgenerational transmission of the Holocaust survivor Chaim Pomerancblum's life story, and of reflecting, at the same time, on this non-canonical practice in the academic world regarding the use of first person narrative. First, I will discuss and explain this self-reflective approach by drawing on post-memorial literary and theoretical works. Next, I will narrate, in a fragmentary and metatextual way, the life story of Chaim, my maternal grandfather.

\section{Keywords:}

Holocaust, postmemory, narrativization, testimony 
Meu avô não gostava de falar do passado. O que não é de estranhar, ao menos em relação ao que interessa: o fato de ele ser judeu, de ter chegado ao Brasil num daqueles navios apinhados, o gado para quem a história parece ter acabado aos vinte anos, ou trinta, ou quarenta, não importa, e resta apenas um tipo de lembrança que vem e volta e pode ser uma prisão ainda pior que aquela onde você já esteve.

Michel Laub, Diário da queda

Abordarei neste ensaio a história de um "sobrevivente ordinário" da Shoá : Chaim Pomerancblum, judeu polonês nascido na pequena Staszów² em 1910 e que migrou para o Brasil em 1946 depois de passar por pelo menos três campos de concentração e de perder praticamente toda sua família nuclear. O que me interessa realmente é a memória transgeracional dessa história, mas sobretudo a memória da sua transmissão. Ou seja, a maneira como sua história de vida foi transmitida para sua esposa, filhos e netos e sobretudo como seus descendentes percebem essa transmissão.

A particularidade desta análise é que esse homem é o meu avô materno, e parte das memórias transmitidas e relatadas aqui são as da minha própria infância. A forma deste trabalho é voluntariamente e necessariamente híbrida. Parti do testemunho dado pelo meu avô em 1988, das minhas memórias das narrativas de transmissão, de objetos - cartas, joias, documentos fiz longas entrevistas semi-diretivas por videochamada com suas filhas e outra neta, uma antes e outra depois de elas ouvirem a entrevista de Chaim na íntegra.

Em termos teóricos, interessei-me por abordagens voltadas para a "narrativização" da experiência traumática, de viés literário e em estreito diálogo com os estudos culturais, mas também de viés histórico, psicanalítico, sociológico? ${ }^{3}$ Esse trabalho se inscreve na junção entre pesquisa acadêmica e busca pessoal. Por tudo isso, antes de abordar a história do meu avô, é necessário justamente refletir sobre essas questões.

Zeide, avô em iídiche, como todos os netos o chamavam, foi para mim "o sobrevivente da Shoá": herói, vítima, pedaço vivo da história, mas também silêncio e mistério. Chaim era "o meu sobrevivente da Shoá", habitando assim todos os romances, filmes, documentários, museus, monumentos, diários, testemunhos, livros de história e historiografia relativos à Shoá e tudo que tenho lido e assistido sobre memória e pós-memória de experiências traumáticas. Escutei o testemunho na íntegra pela primeira vez em 2019 enquanto encaixotava meus pertences para mais uma das minhas inúmeras mudanças de casa. Ouvir a voz do meu avô falando sobre a Shoá me tocou de maneira particular naquele momento porque eu já vinha trabalhando com o conceito de pós-memória em relação à ditadura brasileira. Reconheci com emoção a voz de Chaim, mas percebi como sabia pouco sobre o passado dele e, pela primeira vez, isso realmente me incomodou. Era como se o fato de ele ser "o meu sobrevivente" já contivesse em si uma narrativa pronta e que esta remetesse a todas as narrativas de perseguição, exílio e perdas, próprias ao que se pode chamar de uma memória cultural compartilhada da Shoá. 
Era como se todas as histórias da Shoá fossem uma mesma história. E eu estava justamente à procura da outra face dessa memória, algo mais pessoal. A verdade é que no testemunho do meu avô não parecia haver interioridade ou subjetividade e que ele não conseguia sair de um contar que me parecia sempre breve demais, desprovido de detalhes e de sentimentos, o que era surpreendente, considerando que todas as minhas outras lembranças de Chaim remetiam a um homem bastante afetuoso.

A partir dessas constatações, comecei a conversar com minha mãe, Leia Heineberg, filha primogênita de Chaim, com a qual eu já havia feito algumas pesquisas sobre a passagem de Chaim por Paris depois da liberação dos campos de concentração. Em 2016, Leia fizera uma viagem à Polônia em busca de detalhes da história do pai, visitara Staszów, passara pelos lugares em que Chaim teria vivido e mantido a sua relojoaria de acordo com os raros indícios que tínhamos. Foi Leia quem me passara o $\mathrm{CD}$ da entrevista do meu avô em uma de suas vindas à França, quando as fitas das cassetes já estavam obsoletas e ela tivera o cuidado de atualizar a tecnologia. Conversando com a minha mãe, pude contextualizar um pouco mais o testemunho. A entrevista de Chaim fora concedida no âmbito do projeto de preservação da memória da comunidade judaica do Rio Grande do Sul do Instituto Cultural Judaico Marc Chagall (ICJMC) que teve início em 1986, focalizando-se particularmente em histórias de vida de imigrantes judeus de origens diversas. ${ }^{4}$ Hoje são 600 entrevistas das quais apenas 13, incluindo a do meu avô, com sobreviventes da Shoá.

Intrigada pelo silêncio, pelas contradições e pelo que me pareceu a desmemória do meu avô, decidi enviar o depoimento, agora convertido em MP3, a algumas pessoas da família, sobretudo à minha mãe e à minha tia Mery Pomerancblum Wolff. O terceiro filho de Chaim, Leonardo Pomerancblum, acabara de sofrer um acidente e encontrava-se naquele momento com a fala bastante comprometida. Naquela altura, a busca pessoal já se tornara uma proposta de comunicação e, pelas conversas preliminares com a família Pomerancblum, vi que seria importante limitar as entrevistas sob pena de não conseguir tratar todo o material a tempo. Optei pelo recorte da transmissão feminina, ou seja, as duas filhas e suas respectivas filhas, minha prima Fabiane Wolff, filha de Mery, e eu. Essa escolha não se deu apenas por questões práticas. Na família, era unânime e às vezes até motivo de piada o papel da minha avó Fanny Pomerancblum como porta-voz, tradutora, intermediária e acima de tudo escudo do meu avô Chaim. Foi sobretudo através da narrativa dela que soubemos o pouco que sabemos sobre a vida de Chaim na Polônia. Optei então por seguir a linhagem feminina da família, até porque, de maneira intuitiva, percebia dois modelos diferentes de construção narrativa que as duas filhas de Chaim incarnam, como veremos mais adiante.

Eu poderia ter escolhido algum romance brasileiro relacionado à Shoá para abordar no colóquio Sous des cieux étrangers, organizado por Karina Marques e Sandra Teixeira na Universidade de Poitiers em novembro de 2020. Eu já havia pensado em analisar Diário da queda (2011), de Michel Laub, meu primo pelo meu lado paterno. Embora o romance tenha muitos ecos do outro lado da família do Michel, é impossível não ver no personagem do avô de Diário da queda uma ligação com Chaim. Mas, como bem mostra a epígrafe que escolhi para este texto, 
Cadernos de Literatura Comparada

Apesar do silêncio: heranças da experiência da Shoá de Chaim Pomerancblum

analisar Diário da queda não seria também falar do meu avô e, no fundo, de mim? A passagem do registro ficcional para o testemunhal me trouxe dúvidas em relação à minha legitimidade para tratar de uma história de vida em vez da ficção, mas também fiquei bastante constrangida com o emprego da primeira pessoa do singular.

Fui sensível à advertência de Beatriz Sarlo em Tempo passado (2005) sobre a guinada subjetiva nas ciências humanas, na qual este texto se insere. A aceitação da guinada subjetiva e do meu posicionamento enquanto sujeito e, de certo modo, enquanto objeto, tornou-se possível graças ao trabalho de Leonor Arfuch, que amplia as delimitações dos diferentes gêneros de escrita de si na contemporaneidade através do conceito de "espaço biográfico contemporâneo": um lugar de "confluência de múltiplas formas, gêneros e horizontes de expectativas" (Arfuch 2010: 58). ${ }^{5}$ Arfuch baseia-se no conceito bakhtiniano de intertextualidade para mostrar que a subjetividade contemporânea, marcada pelo descentramento do sujeito, é híbrida por definição e se expressa em gêneros narrativos bastante diversos como o testemunho, a entrevista midiática, o relato de vida das ciências sociais, além dos gêneros literários já clássicos, como a autobiografia, as confissões, o romance biográfico e a biografia, ou menos clássicos, como a autoficção. Ou seja, a proposta de Arfuch, deixou-me mais à vontade, tanto para transitar da literatura para o relato de vida quanto para valer-me da minha posição acadêmica para abordar uma questão pessoal de maneira autoreflexiva. De resto, a dimensão ética trazida pelo conceito de identidade narrativa de Paul Ricœur (1990) torna esta primeira pessoa que aqui utilizo consciente do necessário desdobramento do "o si-mesmo em um outro", ${ }^{6}$ da necessidade de buscar a minha própria voz.

O que proponho a seguir é uma narrativa pós-memorial nascida das leituras teóricas mencionadas acima e também de autores como Marcel Cohen de Sur la scène intérieur (2013), Noemi Jaffe de Com quem os cegos estão sonhando (2012) e Daniel Mendelsohn de The lost (2006), que escrevem a partir de rastros memoriais. Já que escrita de si e teoria pós-memorial dividem na contemporaneidade um mesmo espaço biográfico, minha intenção aqui é incorporar ao trabalho acadêmico a expressão pós-memorial. Segundo Marianne Hirsch, a produção artística pós-memorial representa o trauma vivenciado indiretamente pelas gerações seguintes ao acontecimento, dando lugar de destaque justamente à narrativa e aos objetos que intermedeiam experiência e expressão. Nas palavras de Hirsch:

"Postmemory" describes the relationship that the "generation after" bears to personal, collective, and cultural trauma of those who came before - to experiences they "remember" only by means of the stories, images, and behaviors among which they grew up. But these experiences were transmitted to them so deeply and affectively as to seem to constitute memories in their own right. Postmemory's connection to the past is thus actually mediated not by recall but by imaginative investment, projection, and creation. (Hirsch 2012: 5)

[O termo "pós-memória" descreve a relação que a "geração seguinte" tem com o trauma cultural, coletivo e pessoal vivido por aqueles que a precederam. Ele diz respeito, portanto, às experiências das quais essa geração só pode se "lembrar" através das histórias, imagens e comportamentos em 
meio aos quais ela cresceu. Mas essa experiência lhes foram transmitidas de maneira tão profunda e afetiva que parecem constituir sua própria memória. A relação da pós-memória com o passado é, na realidade, assegurada pela mediação e não por lembranças, mas por investimentos imaginativos, projeções e criações.]

Por isso, a geração pós-memória tem uma estética marcada pela autoconsciência. Luba Jurgenson chega a falar em metalepse, no sentido genettiano do termo, ou seja:

una inversión de temporalidades: la anterioridad de la obra en relación con la crítica, la dependencia de la crítica para con su objeto, quedan cuestionadas cuando la obra anticipa su recepción o incorpora enunciados exegéticos, o incluso cuando interpela al comentarista. El componente metatextual de los relatos contemporáneos que integran une parte reflexiva sobre su propia emergencia conduce ciertamente a los autores a apropiarse de la palabra crítica, indisociable en adelante del dispositivo ficcional. La literatura, por otra parte, siempre tendió a revestir su morada con los espejos que le tendían los críticos. Preocupada por neutralizar os esquemas destinados a capturarla, los desactiva poniéndolos escena, haciéndolos pasar de fuentes secundarias lo que suelen ser - a fuentes primarias, transformándolos en una parte de sí misma. (Jurgenson 2020: 620)

[uma inversão de temporalidades: a anterioridade da obra em relação à crítica, a dependência que a crítica tem em relação a seu objeto, se veem contestadas quando a obra se antecipa à sua recepção ou incorpora enunciados exegéticos ou ainda interpela o comentador. O componente metatextual das narrativas contemporâneas que integram uma parte reflexiva sobre a sua própria emergência, leva naturalmente os autores a se apropriarem da palavra crítica agora indissociável do dispositivo ficcional. A literatura, de resto, sempre teve a tendência de enfeitar sua morada com os espelhos que a crítica lhe oferecia. Preocupada em neutralizar os esquemas destinados a capturá-la, desativa-os performando-os, fazendo com que passem de fontes secundárias - o que são apenas - a fontes primárias, transformado-os em parte de si mesma.]

Ao abordar especificamente o texto literário, Luba Jurgenson explica que a literatura pós-memorial incorpora mecanismos de mise-en-abyme que autenticam o relato revelando, pelo próprio gesto, a gênese da narrativa, mas também os procedimentos próprios à crítica literária e acadêmica pós-memorial. Podemos, então, pensar que a teoria e a crítica universitárias que tradicionalmente se encarregam de analisar as expressões artísticas, provavelmente por influência de seu próprio objeto, também têm incorporado procedimentos da literatura pós-memorial. Este é o caso deste trabalho que, ao buscar autenticação e referencialidade em documentos, objetos, memórias familiares e entrevistas, por ser escrito na primeira pessoa e situar-se num momento de descentramento do sujeito, incorpora a própria literatura pós-memorial.

A partir dessas observações preliminares, proponho apresentar, a partir de agora, a memória transgeracional da experiência traumática de Chaim Pomerancblum através de fragmentos 
que, ao meu ver, ilustram tanto a história de vida do meu avô quanto a maneira como se deu a sua transmissão. A parcialidade de toda história de vida parece-me ainda mais insistente quando documentos, fotografias, notícias de jornais, objetos, lembranças e narrativas desapareceram em circunstâncias trágicas. Para falar de Chaim Pomerancblum, precisei incorporar essa incompletude ao próprio narrar, do mesmo modo que o silêncio era quase sempre a forma de expressão do meu avô.

\section{Sabíamos, mas Chaim não contava}

Eu sempre soube que Chaim perdeu toda sua família nuclear durante a Segunda Guerra Mundial, com exceção da meia-irmã Ruchla Lipskind que se exilara no Brasil em 1933 com o marido, abrasileirando seu nome para Raquel. Eu sempre soube que meu avô migrou para o Brasil mais de um ano depois do final da guerra, quando conseguiu localizá-la. Eu sempre soube que Chaim consertou relógios de muitos oficiais alemães, eu sempre soube que entre os trabalhos forçados que realizou, estavam a construção de estradas e a fabricação de munições. Mas nunca presenciei Chaim contando sobre o extermínio da sua família. Nunca ouvi Chaim descrevendo o que viveu nos campos de concentração. Minha avó Fanny, que chamávamos de Babi (numa adaptação ao português do iídiche Bubbeh), sempre falava sobre isso longe dele, baixando um pouco a voz como se nos contasse um segredo que precisasse muito esconder de Chaim. Leia, Mery e Fabiane também são unânimes: elas também sempre souberam que Chaim era um sobrevivente, antes mesmo de poder entender o que isso significava. Mas nunca ouvimos uma narrativa sobre o assunto feita diretamente por Chaim.

\section{Um túmulo}

Com as filhas, não foi muito diferente dos netos, Chaim não conversava sobre a experiência da Shoá. Leia e Mery ouviam falar em "sobrevivente", "guerra", "segunda guerra". Segundo Mery, nem mesmo as palavras "Holocausto" ou "Shoá" eram pronunciadas em casa. A impressão de Leia é que os pais queriam preservar os filhos "para não criar traumas" (Heineberg 10/10/2020). Minha tia Mery explica que, além de Chaim não falar, Fanny queria protegê-lo. "Eu acho que era como se fosse proibido falar. Ele não falava e a mãe não deixava perguntar" (Wolff 26/08/20). Mery conta:

O único documento que eu via na infância era aquela maguen David [estrela de Davi] no pano amarelo. Uma vez a mãe me mostrou. Eu não sei se eu perguntei como é que ela sabia, como é que ela tinha certeza que ele tinha estado na guerra então ela me mostrou aquilo comprovando. Mas eu nunca tive acesso na minha infância a cartas, a documentos, nada. Era quase que um túmulo. Sobre a experiência do meu pai no campo de concentração era um túmulo que eu não podia ter acesso, que isso faria doer no meu pai e que eu não podia perguntar. E isso, durante toda a minha infância. (ibidem) 
Curioso o uso da palavra túmulo, empregada em várias línguas para qualificar alguém que não fala e sobretudo não revela um segredo de maneira alguma. Mas, no caso da Shoá, bem como de outras experiências traumáticas, o sentido denotativo (tumba) e o sentido figurado (do segredo) se completam e se explicam.

\section{Desmemória}

Na entrevista de 1988, a memória de Chaim parece bastante comprometida: longos silêncios pontuam a enumeração dos nomes dos três filhos, nora e genros e dos sete netos com os quais tinha muito contato. Ele confunde datas e lugares. Mas tanto Mery quanto Leia não têm a menor dúvida: Chaim estava bem de saúde e lúcido em 1988. Eu não tinha essa impressão e, para mim, ele já era um homem que se lembrava pouco e quase não se comunicava quando eu tinha 13 anos. Na narrativa que construí para mim, atribuía a desmemória e o silêncio de Zeide à cirurgia que ele fez logo que se aposentou em 1981 para extrair um tumor do cérebro. A operação deixou sequelas: uma perna pesada que dificultava os deslocamentos, mas, objetivamente, Chaim ainda não tinha sinais de demência, o que viria a ocorrer efetivamente anos mais tarde por problemas circulatórios.

Concluo, então, que Chaim não estava silencioso e desmemoriado por questões de saúde em 1988, ele era silencioso. Desmemória e silêncio se confundiam nele e nos confundem até hoje.

\section{Traduções}

"Certamente se Zeide tivesse testemunhado em iídiche, o resultado seria diferente", penso depois de ouvir o documento dezenas de vezes sem conseguir dar sentido para o que meu avô diz, num discurso que nunca parece ter um encadeamento lógico. Chaim certamente contou o que passou em iídiche para Fanny. Depois, naturalmente sem ter muita consciência disso, Babi selecionou, traduziu e adaptou antes de nos transmitir fragmentos dessas histórias, sempre os mesmos, repetidos e contados em voz baixa e de maneira breve. Nunca nos estendíamos nesse assunto. Ocorre-me a ideia de que, no depoimento de 1988, Chaim estivesse tentando recuperar a narrativa de Fanny contando a história dele e não aquilo que ele próprio havia vivido. E talvez o fato de retomar as palavras da minha avó sobre a sua própria história gerasse a confusão que me pareceu desmemória. Mas essa confusão do meu avô não vem apenas da sua falta de vocabulário em português e da mediação de Babi. Parece ter a ver com o fato de Chaim não ter elaborado uma narrativa, de ter consertado muitos relógios justamente para não pensar no assunto.

\section{Eufemismos}

Uma marca do discurso testemunhal de Chaim é a maneira que ele tinha de amenizar os seus sofrimentos, ou melhor, de nunca falar dos sofrimentos como tais, mas como algo que poderia ter sido ainda pior. Isso acontece quando ele responde sobre os trabalhos forçados que realizou: 
ICJMC: O senhor me disse que ficou dois anos no campo.

Chaim: Sim.

ICJMC: Dois ou mais anos?

Chaim: Dois ou mais anos, um tempão que eu estive, porque antes eu estive na minha cidade. Também trabalhava na estrada onde precisava de trabalho, daí não gostei, melhor ir no campo, não precisava ir na estrada, daí trabalhei no campo. Trabalhei... aonde trabalhei? (Instituto Cultural Judaico Marc Chagall 1988)

Fico perplexa ao ouvir Chaim dizer tão claramente, nesta passagem confusa do seu depoimento, sua "preferência" pelo campo de concentração em detrimento do trabalho na construção de estradas. Depois de ver e rever imagens dos prisioneiros de Buchenwald durante a liberação, ou seja, justamente o campo onde meu avô se encontrava naquele momento, tentei imaginar os horrores de algo ainda pior, que fez o meu avô "preferir" um inferno em relação ao outro. Mas obviamente ele sequer teve escolha.

\section{Maneiras de esquivar}

Uma das estratégias discursivas que aparece de maneira recorrente na entrevista consiste em repetir as palavras da entrevistadora. Fabiane (12/10/2020) me lembra que ele fazia isso conosco também: incluía na resposta parte da pergunta e acrescentava mais alguma palavra que provavelmente esperávamos ouvir e, assim, ele pensava ficar tranquilo e silencioso por algum tempo. No próprio trecho citado acima ele retoma parte da pergunta da entrevistadora "dois ou mais anos" ao responder sobre o tempo em que foi prisioneiro em campos de concentração.

Ouvindo a voz de Zeide, eu lembrei de uma expressão bastante banal que ele costuma usar: "é lógico". Provavelmente por eu não ter o hábito de usá-la, chamava minha atenção. Ouvi de novo a entrevista tentando encontrar um exemplo disso para confirmar essa lembrança. Encontrei o seguinte:

ICJMC: Qual foi sua impressão, quando chegou aqui, o que o senhor achou de Porto Alegre, quando o senhor chegou? Era diferente da Polônia?

Chaim: Era, lógico que era diferente da Polônia!

ICJMC: Eu quero que o senhor me fale. Eu sei que era, eu quero que o senhor me conte. (Instituto Cultural Judaico Marc Chagall 1988)

O desconcerto da entrevistadora diante da resposta do meu avô é evidente pois a resposta dele não deixa margem alguma para o narrar. "É lógico", no discurso do meu avô, se opõe a contar, pois supõe que o interlocutor já sabe, já tem o repertório e talvez que os livros, jornais e outras testemunhas já o tenham contado. 


\section{Sotaque}

Devia ser pelo fato de Chaim falar pouco que era difícil definir o sotaque dele. Ele não tinha dificuldade de pronunciar a maioria dos sons da língua portuguesa, como era o caso dos meus avós paternos, que eram alemães. Pelo que indicam cartas recebidas em polonês e o fato de ele ter estudado por um curto período em um colégio público, meu avô tinha conhecimentos pelo menos razoáveis de polonês, uma língua rica em fonemas que deve ter ajudado na pronúncia do português. Sabia o hebraico litúrgico, mas a língua em que ele se sentia mais à vontade era certamente o iídiche. "Era esse o sotaque dele", segundo a minha prima Fabi, "um sotaque iídiche!" (Wolff, 26/08/2020) O rastro do iídiche estava sobretudo na melodia, na musicalidade.

No testemunho, Chaim engana-se na conjugação de alguns verbos ("eu fugiu"); utiliza registro coloquial acreditando adotar uma certa formalidade ("um tempão!"), troca palavras ("maioridade" por maioria) e por vezes os "ãos" e "ões" não saem tão anasalados como deveriam. Achei particularmente comovente o uso de certos regionalismos gaúchos, como "guri", que lembro de ele usar com frequência. Aliás Chaim gostava de tomar chimarrão, sempre com uma colher de mel. Pouco a pouco, não apenas o país de adoção, mas também a região, vão sendo incorporados ao mundo de Chaim.

\section{Em que língua?}

Em que língua contar o que se tem chamado de indizível?? É possível contar numa língua de adoção, embora, como justifica Mery (Wolff 26/08/21), ele tenha trabalhado usando o português durante mais de três décadas? Se ele contou suas experiências traumáticas à minha avó em iídiche, língua que falavam entre si, como traduzi-lo para o português senão com as palavras que Fanny usava para nos contar suas histórias? De onde tirar palavras em português para narrar o que não merecia ser revivido e que sua experiência no Brasil felizmente não lhe dava repertório?

\section{Algumas coisas que sabemos da cronologia e dos lugares pelos quais Chaim passou durante a Shoá}

Alguns documentos e relatos permitem retraçar fragmentos da história de vida de Chaim, desde a transformação de Staszów em gueto, em 1942, até a chegada dele ao Brasil. O Staszów Book (1962) permite cotejar lugares e datas e encontrar alguns marcos na linha de tempo da história do meu avô durante a Segunda Guerra. Por exemplo, como Chaim, a maioria dos jovens da sua cidade foi deportada para o campo de Skarżysko-Kamienna e trabalhou na fábrica de munição deste, onde havia também minas submarinas, conhecidas como inferno amarelo (Mémoires des déportations Por que em francês?). Skarżysko é aliás o único campo que Chaim menciona no depoimento dado ao ICJMC. Isso me chamou a atenção pois nem eu, nem minha prima nem sequer minha tia Mery lembrávamos de menções a esse campo na história de Zeide. Chaim também contava, como vimos, que trabalhara na construção de estradas. Em $1^{\circ}$ de agosto de 1944, o campo de Skarżysko foi fechado. Não temos certeza se Chaim ali ficou até esta data. Foi talvez nesse momento que ele tenha trabalhado em estradas ou sido transferido 
Cadernos de Literatura Comparada

Apesar do silêncio: heranças da experiência da Shoá de Chaim Pomerancblum

diretamente para o campo de Buchenwald, na Alemanha, onde permaneceu até a liberação. De Buchenwald, temos registros. São documentos do próprio campo que meu irmão Ricardo Heineberg conseguiu consultar e reproduzir quando visitou o Holocaust Museum em Washington e que agora podem ser facilmente acessados nos arquivos de Arolsen. Chaim ingressou no campo em 8 de setembro de 1944. Permaneceu em Buchenwald até a liberação do campo em 11 de abril de 1945. Mas depois da liberação ainda foi conduzido pela Cruz Vermelha para o campo de Theresienstadt ou Terezín, na atual República Checa. Como muitos prisioneiros de Buchenwald, Chaim estava esgotado e doente, sem possibilidades de sair do campo por seus próprios meios (Hackett 1998).

\section{Ficha médica de Buchenwald}

Numa das fichas, fico sabendo algumas informações que os funcionários do campo acharam importante registrar sobre o prisioneiro 84.928 . Altura: $165 \mathrm{~cm}$; peso: 50 quilos; profissão: relojoeiro; histórico médico: tifo em 1920, hérnia inguinal em 1923, nefrite em 1938; pé chato. Se Chaim teve tifo aos dez anos, infiro que as condições sanitárias em que ele vivia já não eram das melhores na Polônia de sua infância. Minha mãe não se convence com algumas informações inscritas pelos nazistas quando lemos juntas essa ficha para decifrá-la. Por exemplo, o peso de $50 \mathrm{~kg}$ não parece condizer com as condições pelas quais passara até ali, parece-lhe uma forma de maquiar a realidade. Eu construo a hipótese que talvez tenha sido no campo de Buchenwald que ele realmente minguou. Por que os nazistas tentariam engordá-lo em suas fichas? Se Chaim não contava as situações pelas quais passara, há um número da história dele que eu nunca esqueci: 36 . Trinta seis era o peso de Chaim quando Buchenwald foi liberado. Era o único dado concreto de que eu dispunha sobre o meu avô. Quando ultrapassei este peso na adolescência, embora eu não tenha chegado à altura do meu avô, lembro perfeitamente de ter tentado imaginar o corpo de um homem com este peso de criança.

\section{Algumas coisas que sabemos sobre o período do final da guerra à chegada de Chaim ao Brasil}

Esta parte da história está mais documentada e renderia um artigo à parte. Quando Chaim começa a ganhar forças, sai do campo de Theresienstadt, provavelmente em busca de parentes sobreviventes e para reconstruir sua vida. Recebe um salvo-conduto em 14 de agosto de 1945 para ir a Lodz, onde tinha grande parte de sua família, e um outro em 20 de setembro para a região Piotrkow. Passa por Bruxelas, onde recebe do consulado polonês um certificado de nacionalidade em 3 de novembro de 1945. Em 9 de novembro já o encontramos em Paris, vive num abrigo na Rue des Rosiers, no Marais, bairro onde mais de meio século depois eu costumava comer beigels nos domingos. Logo Chaim começa a trabalhar como relojoeiro. A passagem dele por Hervais, situado no $\mathrm{n}^{\circ} 8$ da Place de la Madeleine, está documentada. Chega a ganhar 3000 francos por semana. Aluga então um apartamento na Rue de Flandre. Há ainda documentos de trabalho, de comprovação da nacionalidade polonesa, uma autorização para ir ao porto de Marseille, pois eram indispensáveis para a sua viagem ao Brasil. Com a ajuda de associações internacionais, Chaim consegue entrar em contato com a irmã. Temos a carta que Chaim envia 
à Raquel anunciando que vai ao Brasil ao encontro dela.

Paris, 14/11/1945

Minha querida irmã e cunhado,

Eu fiquei sozinho de toda família. Eu ando para cá e para lá sem uma casa, procurando por familiares sem encontrar ninguém. Eu vou vir encontrar com vocês. Esta é a minha última esperança. Não me preocupo por me sustentar porque ganhar sempre eu vou poder pois eu vou trabalhar. Fui ao cônsul do Brasil [sic] e ele me disse que vou receber de ti um telegrama que tu me queres perto de ti. Vou poder ir para junto de ti, com as despesas da viagem vou dar um jeito. Seria melhor se ganhasse uma passagem de navio. Mas eu não sei se é possível. Mas o primeiro de tudo é um telegrama. (Carta de Chaim Pomerancblum a Raquel Lipskind)

A carta foi traduzida pela minha avó depois da morte de Zeide, em 1996, enquanto minha mãe anotava (eu a transcrevi acima tal e qual). No final, Chaim menciona que está na casa de uma prima em Paris, Raise, que por sua vez rabisca um bilhete em polonês para Raquel. Quem seria ela? Leia e Mery nunca ouviram falar de Raise, sendo que ela sobreviveu à guerra e ainda conviveu com o meu avô em Paris. Não sabemos por que ele não deu continuidade aos poucos contatos que restaram de sua antiga vida na Polônia.

Um detalhe que chama a minha atenção foi Zeide ter guardado tão preciosamente os cartões de visita de vendedores de peças de relógios de Paris que minha mãe tem até hoje. Leia me contou que Chaim levou muitas peças consigo para o Brasil. Consertar engrenagens sempre foi a perspectiva de presente e futuro de Chaim.

\section{Filha historiadora}

O que significa para uma filha de sobrevivente se tornar historiadora e trabalhar com arquivos? A minha mãe preza o registro de datas e lugares. Sabe números de telefone de cor. Não esquece de datas de aniversário inclusive de amigas minhas de infância com quem hoje tenho pouco contato. Gosta de saber a grade de horários de atividades dos meus filhos que moram na França e sabe todas essas coisas de cabeça enquanto eu preciso olhar na agenda. No que diz respeito ao meu avô, ela reuniu, digitalizou e arquivou todos os documentos. Ela se incomoda por não conseguir retraçar a cronologia certa. Por haver lacunas de datas e lugares. Mas, sobretudo, por Chaim não ter transmitido o contato de alguns parentes no resto do mundo com os quais ele mantivera alguma relação. Por nunca ter compartilhado com os filhos os nomes dos membros de sua família e a relação de parentesco. No depoimento que meu avô deu ao ICJMC, ouvimos a chegada de Leia para ouvir o depoimento. Ela quer rastros dos fatos.

\section{Filha psicanalista}

Minha tia Mery está menos a par da cronologia e dos topônimos do que a minha mãe. Minha mãe chega a cobrá-la por isso. Mas minha tia tem lembranças bastante detalhadas de Zeide contando para ela o quanto fazia frio na Polônia antes da guerra a ponto de o nariz pingar 
Cadernos de Literatura Comparada

Apesar do silêncio: heranças da experiência da Shoá de Chaim Pomerancblum

e o pingo congelar antes mesmo de cair ou das batatas guardadas no porão durante o inverno, ou da parede falsa construída para esconder algumas joias ou pratarias da família. Mery conta de maneira emocionada e tocante como se sentia por ter pais mais velhos, ambos imigrantes (minha avó viera de Tarnow na Polônia, em 1927), ao passo que a maioria dos seus colegas de escola tinha pais nascidos no Brasil e já bastante adaptados. Embora os filhos de Chaim tenham estudado numa escola judaica, Mery confidencia que se sentia diferente dos demais. Tinha um pai para o qual não era possível fazer perguntas, o medo de machucá-lo ou de se machucar com o passado do pai estava sempre muito presente. Quando Mery foi pedir ao pai para fazer terapia, etapa essencial da sua formação como psicóloga e depois psicanalista, Chaim respondeu: "faz autoanálise, eu faço autoanálise". Mas Chaim prezava os estudos acima de qualquer coisa e quando Mery finalmente explicou que a terapia fazia parte da sua formação profissional, ele acabou por aceitar arcar com as despesas do tratamento.

Fico pensando que talvez Zeide tivesse dito consigo mesmo que a análise para minha tia era indispensável, como o eixo minúsculo de um relógio de pulso o era para um relojoeiro.

\section{Desaparecimentos}

Desapareceram objetos de prata cimentados em paredes duplas da casa de Staszów. Desapareceu a última foto de Chaim com duas de suas irmãs e a mãe, tirada na frente da loja, que Leia e Mery lembram perfeitamente de terem visto ainda adultas. Desapareceu a segunda página de um artigo do vespertino Diário da noite que entrevista Chaim, primeiro sobrevivente da Shoá a migrar para o Rio Grande do Sul logo depois de aterrissar do Rio de Janeiro. Título: "Do campo de concentração para a liberdade", mas o recorte se deteriorou e também não temos a data. É na segunda página, justamente a desaparecida, que Chaim "conta sua odisseia". Imagino que em 1946 ele talvez ainda pudesse falar sobre o que acabara de passar. Será que naquele momento, logo depois de reencontrar a irmã Raquel e o cunhado Rafael, de conhecer o sobrinho Jacó, ele teria revelado detalhes da experiência dos campos ao jornalista? O subtítulo revela que Chaim comia 100 gramas de pão a cada dois dias. Eu nunca tinha ouvido falar nisso. Apesar de inúmeras buscas, foi impossível localizar o acervo desse periódico efêmero. Ficamos então sem a narrativa de Chaim.

\section{Zeygermakher}

Chaim era um zeygermakher, que literalmente podemos traduzir por "fazedor de relógios", ou seja, era um relojoeiro. Segundo meu avô conta no depoimento, o ofício só era exercido por judeus na Polônia. Ele o aprendera com um tio e sustentava a mãe e uma irmã quando a Polônia foi invadida pela Alemanha em 1939. O Staszów Book dedicava algumas páginas ao ofício, pois a cidade tinha alguns zeigermakher conhecidos, geralmente homens com sólidos conhecimentos religiosos, muitos deles sendo rabinos. Isso se explica pelo fato de a profissão ser considerada "limpa e fácil" pelo Talmud. ${ }^{8}$ Ao narrar a escolha da profissão, bem como a sua opção por um judaísmo tradicional, preterindo a tradição chassídica ${ }^{9}$ de sua família, Chaim estava na realidade sublinhando alguns caminhos que lhe foram providenciais. É à profissão 
que Chaim atribui sua sobrevivência durante a guerra. Primeiro, quando todos os comerciantes judeus foram obrigados a parar de trabalhar, e ele e outros relojoeiros puderam seguir com sua tarefa minuciosa, sob pena de que o tempo parasse na Polônia. Depois, mesmo nos campos, Chaim relata que chegou a trabalhar no seu ofício. Em Paris, conseguiu um emprego que era mais bem pago do que o do cônsul brasileiro em Paris, que, aliás, o desaconselhou a migrar para o Brasil. Finalmente, em Porto Alegre, refez sua vida, trabalhando em relojoarias e depois na sua própria loja. Mas, acima de tudo, acredito que foi a maneira que encontrou de calar-se e ir em frente.

\section{A história da cenoura}

Essa história eu não conhecia, mas tanto Leia quanto Mery a contaram quando perguntei a elas em que momento se deram conta do significado de ter um pai sobrevivente. Mery não lembra se estava com ele ou se lhe contaram a história da cenoura, ela tinha por volta de cinco anos. É mais ou menos assim: Chaim estava consertando relógios no fundo da loja, quando vê cair uma cenoura do saco de uma senhora que passava na rua carregada de compras. Ele instintivamente levanta-se correndo para buscar a cenoura e devolver à mulher.

A história da cenoura se reflete também numa cena que muitas vezes ocorreu diante dos meus olhos, à mesa. No final da refeição, quando Babi estava distraída ou ocupada, Zeide, numa garfada ágil, limpava os pratos dos netos. O gesto poderia até ser cômico, caso meu avô não fosse um sobrevivente.

Qualquer desperdício de comida levava Chaim de volta à Europa dos anos 1940 onde passara fome. Apesar do seu silêncio, o seu corpo não esqueceu.

\section{Não me ataca!}

Quando Chaim estava sentado no seu lugar habitual do sofá assistindo televisão, ele não gostava que os netos, principalmente as netas, começassem a dançar na frente da televisão. Ele costumava assistir um programa chamado Festa baile, apresentado por Agnaldo Raiol, que para mim era enfadonho e interminável. Eu não via outra saída senão me divertir um pouco imitando os convidados ou dançando bem na frente do aparelho que o meu avô fixava. Era então que Zeide exclamava: "Não me ataca!". Ele queria dizer "sai da frente!", mas sempre saía "não me ataca". Ninguém parecia se dar conta disso. Então eu repetia a provocação só para ouvir a frase de novo e conseguir entender o significado dela. Minha mãe e minha tia não lembram disso, o que é normal porque elas nunca estavam lá sábado à noite quando Chaim e Fanny assistiam a Festa baile abraçados. Mas Fabiane, que compartilhou comigo várias noites na casa dos nossos avós também não lembrava da frase.

Depois de dançar na frente da televisão dezenas de vezes para ouvir "não me ataca", ainda pré-adolescente, cheguei à conclusão que aquilo que parecia um erro de tradução do meu avô revelava na realidade um trauma de guerra. Refletindo agora sobre o que eu pensava na década de 1990, concluo que o fato de ele ser "o meu sobrevivente" acabou por determinar toda e qualquer imagem que eu pudesse ter dele. 
Cadernos de Literatura Comparada

Apesar do silêncio: heranças da experiência da Shoá de Chaim Pomerancblum

\section{Queloide}

Lista de alguns biografemas do meu avô a respeito dos campos de concentração e da guerra: fuzilamento da mãe na tomada de Staszów porque ela não pôde passar de um caminhão para outro (tinha o movimento das pernas comprometidos por um acidente vascular cerebral); relógios de oficiais nazistas consertados em troca de uma ração de comida; o colar de pérolas da mãe que Chaim carregou durante toda a guerra nos dedos dos pés e depois deu à minha avó. Uma ou outra joia trocada por batatas velhas; bebês jogados ao alto pelos nazistas e fuzilados no ar num macabro tiro-ao-alvo.

Quando tentamos expandir as narrativas, dar a elas corpo e emoção nem sempre elas fazem sentido. O colar de pérolas nos pés não me parece verossímil nem compatível com a construção de estradas, ou com o trabalho na fábrica de munição. Utilizar joias como moeda de troca parece-me hoje algo bastante arriscado. Sempre faltam datas, lugares, nomes completos. Com o tempo, essas histórias foram se "mitificando", como define Mery, pois elas não vinham "com uma vivência emocional dele", eram como uma "vivência do passado que a gente não podia chegar perto" (Wolff, 30/09/2020).

Escrevendo esses fragmentos, eu associei essa rigidificação da memória traumática a um queloide que aparece numa cicatriz, tornando-a mais densa. Não que a cicatriz de Chaim fosse muito visível, mais víamos mais a proteção criada em torno dela do que a antiga ferida.

\section{Happy end}

Dificilmente associamos uma história da Shoá a um final feliz. Há sobreviventes que calaram, outros, como Primo Levi, que contaram, mas depois não aguentaram. O meu avô passou a vida consertando relógios, inclusive à noite com a desculpa de que podia se concentrar melhor. Nunca tirava férias. Não aprendeu a dirigir. O apartamento que comprou ficava em cima da loja. Esse raio de ação reduzido pelo qual Chaim se movia, revela o quanto ele precisou limitar sua vida para levá-la adiante. Meses depois de fechar a loja para se aposentar, Chaim teve que ser operado para extrair o meningioma cerebral, o que reduziu ainda mais seus movimentos. Com os anos, a memória foi se perdendo também por problemas de circulação. Contando assim, talvez não pareça uma vida feliz.

Mas Chaim e Fanny gostavam de apresentar o encontro deles - ela já considerada solteirona com 29 anos e ele com 36 - como o final feliz que permitia virar todas as páginas ruins. Tiveram três filhos, apesar do medo de Chaim de que os campos de concentração o tivessem esterilizado, o terceiro um menino muito desejado, que o fez dar pulos de alegria, como tantas vezes me contaram. Na minha lembrança, Babi e Zeide sempre estavam de mãos dadas ou abraçados e eram muito carinhosos um com o outro.

Mas mesmo a versão longa desta história nas palavras de Chaim se resume a um minuto e oito segundos:

Chaim: Eu fui ver uma família que estava doente e irmã dela com ela estava junto lá, também visitaram aquela senhora, e daí, quando nós saímos, saímos juntos, daí falamos no caminho. 
ICJMC: Daí o senhor gostou dela?

Chaim: Daí gostei dela e logo, isto era quinta-feira, quinta-feira, justamente, eu cheguei.

ICJMC: Em 1946.

Chaim: Em 1946, logo que cheguei e eu disse para ela que gostei dela e eu quero casar com ela, se ela aceita.

ICJMC: O que ela disse?

Chaim: Ela disse que sim, daí nos casamos. (Instituto Cultural Judaico Marc Chagall 1988)

Era como se o silêncio e a concisão que marcaram suas narrativas da Shoá, contaminassem todas as conversas, tornando-as mínimas.

\section{Outras ausências (em guisa de conclusão)}

Há ainda muitas outras histórias que não foram evocadas aqui. Certamente o meu tio e os meus primos que não entrevistei formalmente contariam outras e de maneiras diferentes. Certamente eles sentem falta de outros objetos, de outros nomes, de outros lugares, de outras palavras. Cada um com suas lacunas, suas faltas. Finalmente, o silêncio e a concisão do meu avô não dão lugar a mais silêncio. Tenho consciência de que produção testemunhal e artística das gerações pós-memoriais levanta suspeitas do ponto de vista histórico por sua subjetividade, dividindo os estudiosos da Shoá. Nunca pensei que falaria ou escreveria um dia sobre o meu avô. Não creio dizer algo novo sobre a Shoá. No entanto achei que tinha algo a dizer sobre a sua transmissão e construção narrativa. Mas acredito que transformar as ausências em palavras era simplesmente necessário para seguir adiante.

\section{NOTAS}

* Ilana Heineberg é professora adjunta de Literatura e Cultura brasileiras na Université Bordeaux Montaigne desde 2006. Defendeu sua tese sobre o papel do romance-folhetim na formação do romance brasileiro na Université de la Sorbonne Nouvelle (Paris 3) em 2004. Continua suas pesquisas sobre o romance do século 19, mas voltada para a circulação internacional da narrativa ficcional e suas traduções na França. Traduziu para o português autores como Flaubert, Balzac, Edgar Morin e Nancy Huston. Atualmente dirige o Girlufi, grupo de pesquisas sobre as literaturas de língua portuguesa que integra o laboratório Ameriber. Tem-se debruçado sobre a literatura contemporânea em temas ligados ao exílio, à pós-memória e a questões pós-coloniais. Organizou dossiês sobre essas temáticas nas revistas Letras raras, Letrônica, Elohi, Letras de hoje e co-dirigiu com Martine Bovo e Silvia Amorim a obra Visions décentrées des Études Culturelles. 


\section{Cadernos de Literatura Comparada}

Apesar do silêncio: heranças da experiência da Shoá de Chaim Pomerancblum

${ }^{1}$ É interessante notar como a noção de ordinário, com algumas variações, tem impregnado o pensamento contemporâneo e a sua produção artística. Está presente em títulos de romances, narrativas e ensaios do final do século XX, como Vie miniscules (Pierre Michon, 1984), L'infraordinaire (Georges Perec, 1989), L'invention duquotidien (Michel de Certeau, de 1990). No que se refere à Shoá, esse campo semântico também foi empregado para analisar tanto a vítima quanto o criminoso, mas também a própria existência de um genocídio: "a banalidade do mal" (Hannah Arendt em Eichmann em Jerusalém, 1963), Ordinary men (Christopher Browning, 1992). Segundo Catherine Coquio (2015: 178), o próprio discurso do testemunho está impregnado pela noção de ordinário, e é nesse sentido que uso este termo para me referir a Chaim Pomerancblum.

${ }^{2}$ Segundo The Staszów Book, a cidade contava 4704 judeus e 3653 não judeus em 1921, ou seja, a população judaica correspondia a $57,5 \%(1962: \mathrm{s} / \mathrm{p})$.

${ }^{3}$ Além dos trabalhos de Marianne Hirsch, que foram fundamentais para a construção teórica deste texto, sobretudo Family Frames (1997) et The generation of Postmemory (2014), minha bagagem teórica se constitui principalmente de autores franceses ou que circularam na França, como Paul Ricœur, Catherine Coquio, Luba Jurgenson et Alexandre Prstojevic, Régine Robin, Pierre Ouellet. Consultar na Bibliografia as referências completas.

4 Dirigido na época por Marlene Kulkes, o projeto conta atualmente com mais de 600 entrevistas voltadas para histórias de vida de imigrantes judeus. O acervo do ICJMC é considerado um dos maiores bancos de dados de história oral do Rio Grande do Sul. Além das entrevistas, o projeto reuniu documentos sobre a imigração. Agradeço Fabiana Pinheiro pelas informações e pelas buscas nos arquivos do ICJMC.

${ }^{5}$ Leonor Arfuch explica que ela parte do conceito de espaço autobiográfico de Philippe Lejune para justamente se contrapor ao narratologista francês, mostrando que a pureza dos gêneros narrativos não fazem sentido na contemporaneidade.

${ }^{6}$ Segundo Arfuch, o conceito de identidade narrativa (Ricœur 1990) também permite ao sociólogo em um contexto de entrevista ou escrita de um relato de vida de "situar-se diante dessa impossível mas necessária narração dos outros, com uma expectativa talvez menos ambiciosa quanto à "verdade" dos ditos - sempre suscetíveis de serem confrontados com a variedade de documentos -, mas mais atenta à materialidade mesma do dizer, à expressão, às modulações, aos lapsos, aos silêncios, às alterações da voz..." (Arfuch 2010 : 257).

${ }^{7}$ A noção de indizível tornou-se praticamente um lugar comum nos estudos sobre a literatura de testemunho e mais especificamente sobre a Shoah. Remeto ao artigo de Luba Jurgenson (2009) que retoma a noção para refletir sobre a sua utilização como maneira de contornar a impossibilidade de narrativização de experiências extremas e para estudar as estratégias narrativas empregadas para dar corpo a esta lacuna.

${ }^{8}$ Essa citação do Talmud, livro que contém a lei oral do judaísmo, aparece no capítulo dedicado aos relojoeiros de Staszów "Watchmakers and Goldsmiths" em The Staszów Book. Podemos encontrá-la na biblioteca online Sefaria, com tradução em inglês em https://www.sefaria.org/Kiddushin.82a?lang=bi

${ }^{9}$ Movimento popular de renovação religiosa iniciado no século XVIII, na Podólia (Ucrânia), por Israel ben Eliezer, conhecido como Baal shem tov (detentor do bom nome). A tradição mística e messiânica que se opunha ao intelectualismo e defendia o entusiasmo encontra um sucesso na Europa Oriental e ajudará as comunidades judaicas a enfrentarem o antissemitismo.

(Wigoder 1996: 436-438) 


\section{Bibliografia}

Arfuch, Leonor (2010), O espaço biográfico, Dilemas da subjetividade contemporânea. Rio de Janeiro, Ed. UERJ.

Coquio, Catherine (2015), Le mal de vérité ou l'utopie de la mémoire. Paris, Armand Colin.

Cohen, Marcel (2013), Sur la scène intérieur. Paris, Gallimard.

Erlich, Elhanan (1962), The Staszów Book (translation of Sefer Staszów), Tel-Aviv, Irgun Yots'e Stashov be-Yisra'el, <https://www.jewishgen.org/yizkor/staszow/staszow. html\#TOC369> (último acesso em 08/07/2021)

Hackett, David A (1998), Relatório Buchenwald. Rio de Janeiro, Record.

Hirsch, Marianne (1997), Family Frames: Photography, Narrative and Postmemory. Cambridge, Massachussetts, London, Harvard University Press.

-- (2012), The Generation of Postmemory: Writing and Visual Culture After the Holocaust. New York, Columbia University Press.

Jaffe, Noemi (2012), Com quem os cegos estão sonhando. São Paulo, Editora 34.

Jurgenson, Luba / Prstojevic, Alexandre (2012), Des héritiers au témoins. L'écriture de la Shoah et la culture européenne. Paris, Éditions PÉTRA.

Jurgenson, Luba (2020), "Puestas en escena de la memoria: algunos dispositivos", in Basile, Teresa / González, Cecilia, Las posmemorias, Perspectivas latinoamericanas y europeas. La Plata/Bordeaux, Universidad Nacional de la Plata/Presses Universitaires de Bordeaux.

- - (2009), "L'indicible: outil d'analyse ou objet esthétique", Protée, 37 (2), pp. 9-19, <https:// www.erudit.org/fr/revues/pr/2009-v37-n2-pr3490/038451ar/> (último acesso em $12 / 07 / 2021)$

Mémoires des déportations (1938-1945), "Lieux d'internement : camps, ghettos". <https:// memoiresdesdeportations.org/lieux-internement/pologne-ghetto-et-campsskarzysko-kamienna> (último acesso em 12/07/2021)

Mendelsohn, Daniel (2006), The Lost , A search of six of six millions. New York, HarperCollins.

Ouellet, Pierre (2012), "Du témoignage à l'âge de la fiction", in Jurgenson, Luba / Prstojevic, Alexandre, Des témoins aux héritiers, L'écriture de la Shoah et la culture européenne. Paris, PÉTRA.

Ricœur, Paul (2003), La mémoire, l'histoire, l'oubli. Paris, Seuil.

-- (1990), Soi-même comme un autre. Paris, Seuil.

Robin, Régine (2012), "Entre témoin et héritier, une certaine inquiétude" in Jurgenson, Luba / Prstojevic, Alexandre, Des témoins aux héritiers, L'écriture de la Shoah et la culture européenne. Paris, PÉTRA.

Sarlo, Beatriz (2005), Tempo passado: cultura da memória e guinada subjetiva. São Paulo, Companhia das Letras.

The Sefaria Library, <https://www.sefaria.org/texts> (último acesso em 12/07/2020).

Wigoder, Geoffrey (ed) (1996), Dictionnaire encyclopédique du judaïsme. Paris, Cerf/Robert Laffont. 


\section{Arquivos, entrevistas e documentos pessoais}

Arolsen Archives, International Center in Nazi Persecutation. Acessível em: https://arolsenarchives.org/fr/ (último acesso em 12/07/2020)

Carta de Chaim Pomerancblum a Raquel Lipskind (14/11/1945), arquivo pessoal, traduzida em 1996 por Fanny Pomerancblum.

Heineberg, Leia (10/10/2020), Entrevista 1 (anterior à escuta do testemunho de Chaim Pomerancblum), realizada via videochamada.

Heineberg, Leia (23/10/2020), Entrevista 2 (posterior à escuta do testemunho de Chaim Pomerancblum), realizada via videochamada.

Instituto Cultural Judaico Marc Chagall. Departamento de Documentação e Memória - Projeto Histórias de Vida. Entrevista Chaim Pomerancblum, dezembro de 1988.

Wolff, Fabiane (22/08/2020), Entrevista 1 (anterior à escuta do testemunho de Chaim Pomerancblum), realizada via videochamada.

Wolff, Fabiane (12/10/2020), Entrevista 2 (posterior à escuta do testemunho de Chaim Pomerancblum), realizada via videochamada.

Wolff, Mery Pomerancblum (26/08/2020). Entrevista 1 (anterior à escuta do testemunho de Chaim Pomerancblum), realizada via videochamada.

Wolff, Mery Pomerancblum (30/09/2020). Entrevista 2 (posterior à escuta do testemunho de Chaim Pomerancblum), realizada via videochamada. 